Note

\section{A Rapid and Sensitive Method for the Determination of Ascorbic Acid using 4,7-Diphenyl-1,10- phenanthroline}

\author{
Nobuhiko Arakawa, Kimiko Tsutsumi, \\ Norlita G. Sanceda, Tadao Kurata \\ and Chōten INAGAKI*
}

Department of Food and Nutrition, Ochanomizu University, Bunkyo-ku, Tokyo 112, Japan

* Laboratory of Nutrition,

Kyöritsu Women's University, Chiyoda-ku, Tokyo 100, Japan

Received December 15, 1980

The 2,4-dinitrophenylhydrazine (DNP) method has been widely used for the determination of ascorbic acid (AsA) in animal tissues, biological fluids, and foods, ${ }^{1 \sim 3}$ but its experimental procedure takes much time and is rather complex. Besides, there might be some possible reaction of carbonyls, especially in biological samples, with DNP reagent to give the colored products and high blank values, and thus might interfere with the determination of AsA. Recently the $\alpha, \alpha^{\prime}$-dipyridyl method, which depends on the specific reduction of ferric ion to ferrous ion with AsA in acid solution, has been frequently used. Though this method is simple and its sensitivity is better than the DNP method, it can be only available for the determination of $\mathrm{AsA}^{4 \sim 8\}}$

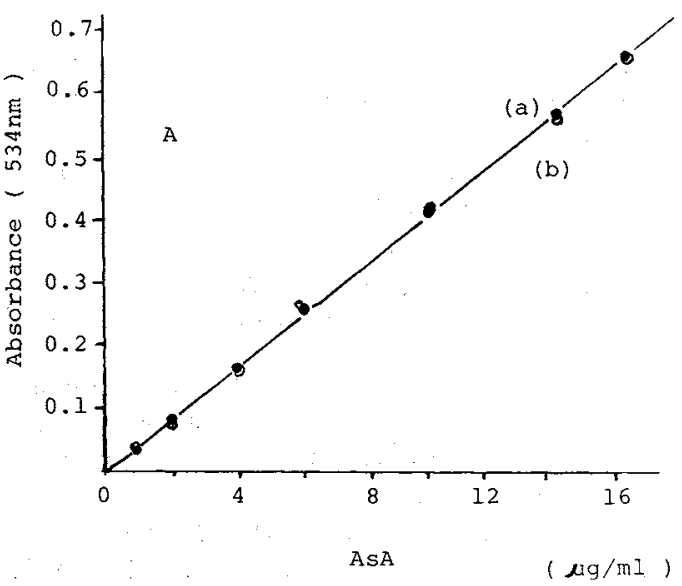

FIG. 1-A. Standard Curve for AsA with DTT (a), or without DTT (b).
In this present study, an attempt is made to use 4,7diphenyl-1,10-phenanthrolin" (Bathophenanthroline, BP) as a suitable reagent, which could be expected to develop a more dense color than $\alpha, \alpha^{\prime}$-dipyridyl reagent. Dehydroascorbic acid (DAsA) is determined after the reduction of DAsA with dithiothreitol (DTT) according to Okamura's method ${ }^{109}$ The principle of the present method relies on reduction of ferric ion with AsA followed by formation of the red colored chelate compound between ferrous ion and BP. A stoicheometric relationship observed between AsA in the sample and formation of the chelate compound is available for the determination of AsA.

Procedure for the determination of AsA: To $1.0 \mathrm{ml}$ of the sample solution extracted in 5\% trichloroacetic acid (TCA) solution add $1.0 \mathrm{ml}$ of $5 \%$ TCA and $1.0 \mathrm{ml}$ of ethyl alcohol (EtOH). The following reagents are added in this sequence; $0.5 \mathrm{ml}$ of $0.4 \% \mathrm{H}_{3} \mathrm{PO}_{4}$-EtOH, $1.0 \mathrm{ml}$ of $0.5 \% \mathrm{BP}$ $\mathrm{EtOH}$, and finally $0.5 \mathrm{ml}$ of $0.03 \% \mathrm{FeCl}_{3}-\mathrm{EtOH}$. The final total volume is $5.0 \mathrm{ml}$. After addition of $\mathrm{FeCl}_{3}-\mathrm{EtOH}$, the solution is allowed to stand at $30^{\circ} \mathrm{C}$ for $90 \mathrm{~min}$ for the $\mathrm{Fe}^{2+}$-BP complex to develop. The absorbance of the color solution is read at $534 \mathrm{~nm}$ in spectrophotometer.

Procedure for the determination of AsA containing DAsA: To $1.0 \mathrm{ml}$ of the sample solution in 5\% TCA add $0.5 \mathrm{ml}$ of $60 \mathrm{mg} \%$.DTT-EtOH and $0.5 \mathrm{ml}$ of $0.2 \mathrm{M}$ $\mathrm{Na}_{2} \mathrm{HPO}_{4}-1.2 \mathrm{~N} \mathrm{NaOH}$ solution to adjust the solution's $\mathrm{pH}$ vlaue at $7 \sim 8$. Then, the solution is allowed to stand at room temperature for $10 \mathrm{~min}$ for DAsA reduction to AsA. After reduction, add $0.5 \mathrm{ml}$ of $240 \mathrm{mg} \% \mathrm{~N}$-ethylmaleimideEtOH to the sample to block the excess of reducing reagent. Add $0.5 \mathrm{ml}$ of $20 \%$ TCA to adjust its $\mathrm{pH}$ value at $1 \sim 2$, to develop a suitable color formation. The following procedures for color formation are the same with those of AsA determination.

Standard curves for AsA assayed with or without DTT

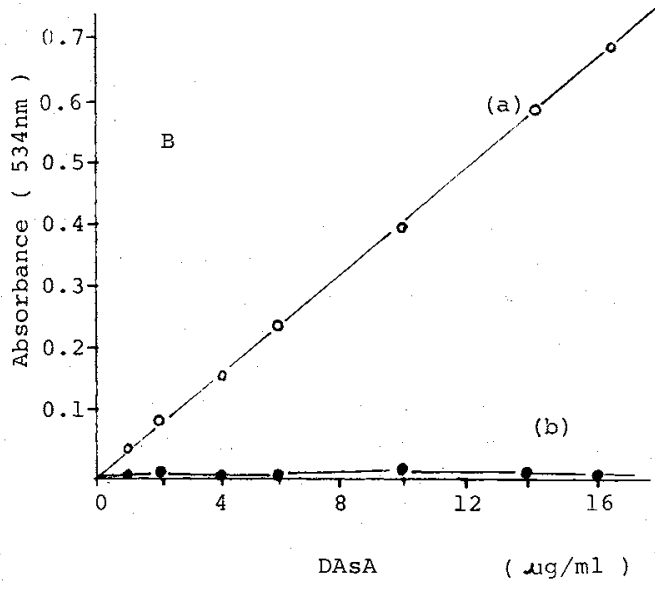

FIG. 1-B. Standard Curve for DAsA with DTT (a), or without DTT (b). 
Table I. Effect of Reducing Substances on Color Development

\begin{tabular}{cccccc}
\hline & \multicolumn{5}{c}{ Absorbance } \\
\cline { 2 - 4 } $\begin{array}{c}\text { AsA conc. } \\
(\mu \mathrm{g} / \mathrm{m} \mathrm{l})\end{array}$ & AsA & GSH & CySH & NADH $_{2}$ & GSH + CySH + NADH \\
\hline 0 & 0.00 & 0.01 & 0.01 & 0.01 & 0.01 \\
2 & 0.13 & 0.14 & 0.13 & 0.14 & 0.14 \\
6 & 0.28 & 0.28 & 0.29 & 0.29 & 0.29 \\
10 & 0.46 & 0.46 & 0.46 & 0.48 & 0.48 \\
14 & 0.60 & 0.60 & 0.63 & 0.64 & 0.64 \\
\hline
\end{tabular}

Amounts of reducing substances in AsA solution (ml): glutathione (GSH), $10 \mu \mathrm{g}$; cysteine (CySH), $13 \mu \mathrm{g}$; reduced form NAD $\left(\mathrm{NADH}_{2}\right), 25 \mu \mathrm{g}$.

Table II. Comparison of AsA and Dasa Contents ( $\mathrm{mg} \%$ ) in Rat Tissues Determined by the Present Method and the DNP Method

\begin{tabular}{|c|c|c|c|c|c|c|}
\hline \multirow{2}{*}{ Tissues } & \multicolumn{2}{|c|}{$(\mathrm{AsA}+\mathrm{DAsA})$} & \multicolumn{2}{|c|}{ DAsA } & \multicolumn{2}{|c|}{ AsA } \\
\hline & BP & DNP & $\mathrm{BP}$ & DNP & $\mathrm{BP}$ & DNP \\
\hline Liver & 40.00 & 40.00 & 9.60 & 9.00 & 30.40 & 31.00 \\
\hline Kidney & 24.60 & 20.30 & 6.60 & 5.30 & 18.00 & 15.00 \\
\hline Adrenals & 172.80 & 159.30 & 70.20 & 58.10 & 102.20 & 101.20 \\
\hline Spleen & 60.00 & 68.30 & 15.60 & 20.30 & 44.40 & 48.00 \\
\hline Plasma & 2.00 & 1.88 & 0.56 & 0.60 & 1.44 & 1.28 \\
\hline
\end{tabular}

are shown in Fig. 1-A. They were linear with a zero intercept and identical slopes (within a range $1 \mu \mathrm{g} / \mathrm{ml}$ to $15 \mu \mathrm{g} / \mathrm{ml}$ AsA solution). As shown in Fig. 1-B, standard curve for DAsA assayed with DTT was superimposable on those of AsA, but color development of DAsA assayed without DTT hardly occurred under the experimental conditions described above. The specificity study in biological samples have shown this method to be highly specific for AsA. Compounds which could possibly interfere with this method such as glutathione, cysteine and reduced form NAD showed no interference. The concentrations of these reducing biological substances in AsA solution shown in Table I corresponded to the maximum concentration which occurred in animal tissues. $^{11)}$

An example of the comparison of AsA contents in rat's tissues determined by the present method and the DNP method is given in Table II. There are agreements with the estimation value of AsA obtained between the present method and the DNP method. The present method has one of its main advantage over the DNP method, the possibility of rapid analyses and has another advantage over the $\alpha, \alpha^{\prime}$-dipyridyl method, more sensitive analyses. Moreover, the present method can spare the centrifusing process required for the $\alpha, \alpha^{\prime}$-dipyridyl method to remove turbidity which sometimes occurred in biological samples. Though DAsA in biological samples except blood has not been determined by the $\alpha, \alpha^{\prime}$-dipyridyl method, the present method could be available for determination of both AsA and DAsA. As this method is very sensitive and requires less time, it would be applicable to autoanalyses of very low concentration biological samples and foods. Details of this study will be reported in a subsequent paper.

\section{REFERENCES}

1) J. H. Roe and C. A. Keuther, J. Biol. Chem., 147, 399 (1943).

2) D. W. Bolin and L. C. Book, Science, 106, 451 (1947).

3) A. Fujita, F. Hirose and Y. Uchiyama, Vitamin, 40, 17 (1969).

4) R. P. Maickel, Anal. Biochem., 1, 498 (1960).

5) V. Zannoni, M. Lynch, S. Goldstein and P. Sato, Biochem. Med., 11, 41 (1974).

6) A. Kyaw, Clin. Chim. Acta, 86, 153 (1978).

7) M. X. Sullivan, H. C. N. Clarke, J. Assoc. Offic. Agr. Chemists, 38, 514 (1955).

8) B. M. Donald, D. W. Lemuel, "Method in Enzymology," Vol. 62, ed. by S. P. Colowick and N. O. Kaplan, Academic Press Inc., New York, N.Y., 1979, p. 9 10 .

9) C. C. Tsen, Anal. Chem., 33, 849 (1961).

10) M. Okamura, Clin. Chem. Acta, 103, 259 (1980).

11) L. Cyril, J. K. Earl, M. S. Warren, "Biochemists' Handbook," E. \& F. N. Spon Limited, 1961. 